\title{
Evaluating the relationship of fasting capillary and venous blood sugar level in self-glucose monitoring device, fasting plasma glucose level and glycosylated hemoglobin $\left(\mathrm{HbA}_{\mathrm{IC}}\right)$
}

\begin{abstract}
Establishing the accuracy of glucose meters however is challenging. A Quantitative Survey research approach was employed in this study under 254 samples, those who are advised for $\mathrm{HbA}_{1 \mathrm{C}}$ test. Baseline data were collected with the help of interview schedule and clinical data of the subjects by a self structured Questionnaire. Subjects were selected by the help of Non-probability purposive sampling technique. Four different parameters were fasting capillary blood sugar value, fasting venous blood sugar value, which were measured through self-glucose monitoring device, fasting plasma glucose level and the $\mathrm{HbA}_{1 \mathrm{C}}$ value of that same sample collected from lab. There is a small but significant difference in the blood glucose results analyzed. So in clinical practice, bedside blood glucose measurements through glucometer may be used by capillary derived specimens and a degree of caution should be worked out in the interpretation of bedside glucometer measurements as they may not be sufficiently accurate to replace laboratory blood glucose results.
\end{abstract}

Keywords: fasting blood sugar, capillary blood sugar, venous blood sugar, fasting plasma glucose level, $\mathrm{HbA}_{1 \mathrm{C}}$, self glucose monitoring device, fasting plasma glucose level
Volume I Issue 3 - 2016

\section{Sasmita Das, Mamata Swain, Rashmimala Pradhan \\ SUM Nursing College, SOA University, India}

Correspondence: Sasmitha Das, SUM College of Nursing, SOA University, India, Tel 09437982 460,

Email das.sasmita2@gmail.com

Received: September 29, 2016 | Published: November 25, 2016

\section{Background}

As International Diabetes Federation (2013), declared that approximately $50 \%$ of all people with diabetes live in just three countries: China (98.4 million), India (65.1 million) and the USA (24.4 million). As already reported WHO (2014) 9\% of adults 18 years and older had diabetes. In 2012 diabetes was the direct cause of 1.5 million deaths. More than $80 \%$ of diabetes deaths occur in lowand middle-income countries. 347 million people worldwide have diabetes. WHO projects those diabetes deaths will double between 2005 and 2030.As Diabetes prevention Program and research group (1999) reported that to prevent diabetes whenever possible and, where not possible, to minimize complications and maximize quality of life. Our core functions are to set norms and standards, promote surveillance, encourage prevention, raise awareness and strengthen prevention and control. As American Diabetes Association ${ }^{1}$ reported that Diabetes care is complex disease and requires patients to take an active role in the management of their disease. Currently, adequate and continuing medical care aiming at preventing acute complications, diminishing risk of long-term complications as well as patient selfmanagement education are considered standard in the care for type 2 diabetes patients. Self-monitoring of blood glucose through capillary blood glucose has already been recognized as an important tool in the control of blood glucose levels of patients with diabetes. The Purpose of the study is to assess the relationship between fasting capillary and venous blood sugar by self glucose monitoring devices (SGMD), fasting plasma glucose and $\mathrm{HbA}_{1 \mathrm{C}}$ value, fasting plasma glucose with fasting capillary and venous blood sugar, which will help in day to day practice of SGMD and continuous monitoring of blood sugar. The relationship of $\mathrm{HbA}_{1 \mathrm{C}}$ and fasting plasma will help the patients to know the mean glucose value of previous 2-3 month by which we can easily manage the blood sugar of diabetic pt. it will also help in patients having continuous insulin therapy.

\section{Aims}

The aims of the study were to assess the correlation four variables those are fasting capillary, fasting venous, fasting plasma glucose value and $\mathrm{HbA}_{1 \mathrm{C}}$ value. To determine the associations between $\mathrm{HbA}_{1 \mathrm{c}}$ and socio- demographic variables. The null hypothesis was there will be no significant association between the $\mathrm{HbA}_{1 \mathrm{C}}$ value and sociodemographic factors.

An exclusive review of literature helped in preparation of data collection tools to assess the relationship among the research variables those are fasting capillary, venous, $\mathrm{FPG}$ and $\mathrm{HbA}_{1 \mathrm{C}}$ value. As American Diabetes Association consensus ${ }^{2}$ reported that Self-management skills have an important role in optimal diabetes control. They enable patients to control their glucose level by recognizing, understanding and act on symptoms related to type 2 diabetes. As Bode ${ }^{3} \&$ DCCT group ${ }^{4}$ informed that the patient is informed how to interpret the results and what actions to take, self-monitoring information can help in making adjustments in direct interacting medication (insulin dosages) and 'lifestyle'. SMBG has been found to be effective for patients with type 1 diabetes. As Shrestha et al. ${ }^{5}$ conducted a study on correlation between fasting blood glucose, postprandial blood glucose and glycated hemoglobin in non-insulin treated type 2 diabetic subjects and reported that postprandial blood glucose correlated better than fasting blood glucose to $\mathrm{HbA}_{1 \mathrm{c}}$. Thus, postprandial blood glucose predicted overall glycemic control better than fasting blood glucose. This finding has potential implications for treatment and monitoring of metabolic control in type- 2 diabetes. ${ }^{6}$ 


\section{Materials and methods}

A Quantitative Survey research approach was employed in this study. The null hypothesis formulated was that there is no significant difference between the $\mathrm{HbA}_{1 \mathrm{C}}$ value and selected demographic variables at 0.05 level of significance. ${ }^{7}$ The study was approved by Institution Ethics Committee. Written consent was sought from each subject. The study was conducted with a sample of 254 OPD patients in IMS \& SUM Hospital, Bhubaneswar, Odisha. OPD patients those were advised for $\mathrm{HbA}_{1 \mathrm{C}}$ test and came for sample collection were the sample of the study. Baseline data were collected with the help of interview schedule for sociodemographic data and clinical data of the subjects by a self structured Questionnaire. Subjects were selected by the help of Non-probability purposive sampling technique. After identifying the patients the researcher was collected the fasting blood sugar sample in four different way and record it accordingly. These four different parameters were fasting capillary blood sugar value which was measured through self-glucose monitoring device by researcher, fasting venous blood sugar value which was measured through self-glucose monitoring device by researcher, fasting plasma glucose level of that same sample which was collected from venous route, that result was collected from central laboratory by the reference no. of client and the $\mathrm{HbA}_{1 \mathrm{C}}$ value of that same sample which was collected from venous route also collected from lab. These four different types of blood samples were collected at the same time. ${ }^{8}$ The data were analyzed by using the descriptive (mean and standard deviation) and inferential (z-test, chi square test and ANOVA test).

\section{Results}

\section{Socio demographic profile of the subjects}

Results of the study revealed that majority of sample that is out of 254 samples $33.5 \%$ of samples were in group of 51-60 years, $57.9 \%$ of the samples were male, according to body mass index depicts that $48 \%$ of the sample were overweight, $82.3 \%$ of the sample were diabetic, and $55.5 \%$ of the sample were type II diabetes. ${ }^{9}$ According to method of checking blood sugar depicts that, $39.8 \%$ were check blood sugar in both hospital lab and self-glucose monitoring device, $60.3 \%$ of the sample were take medication regularly and $54.3 \%$ of the sample were done physical activity regularly. Mean and SD of capillary blood sugar was $145.4 \pm 55.5$, mean and SD of venous blood sugar was $146.0 \pm 55.1$, mean and $\mathrm{SD}$ of $\mathrm{HbA}_{1 \mathrm{C}}$ blood sugar was 163.8 \pm 52.3 , mean and SD of Fasting blood sugar was $145.05 \pm 56.3$.It concludes that the difference between capillary, venous and fasting blood sugar value are very less than each other. So clinically we can use these three types of measurements to know the blood sugar value of the client and it also reveals that $\mathrm{HbA}_{1 \mathrm{C}}$ value is always higher than these three values of that same sample. ${ }^{10}$

\section{Determine the relationship in between the variables}

There was a moderate correlation in between fasting plasma blood sugar and $\mathrm{HbA}_{1 \mathrm{C}}$ value at $(\mathrm{p}<0.05)$ and there were strongly positive correlation in-between fasting plasma, fasting capillary and fasting venous blood sugar value at $(\mathrm{p}<0.05) .{ }^{11}$

\section{Associations of the demographic variables with different parameters}

chi square association of capillary blood value with selected demographic variables that is age, BMI, gender are statistically significant having chi square value $11.834,15.16$ and 4.194 respectively at $\mathrm{p} \leq 0.05$ and the mode of checking blood sugar, regularity in taking medication for DM, physical activity are statistically not significant having chi square value $4.09,5.44$ and 2.79 respectively at $p \leq 0.05 .{ }^{12}$

The chi square association of fasting venous blood value through SGMD with selected demographic variables that is age, gender, BMI, mode of checking blood sugar, regularity in taking medication for DM, physical activity are statistically significant having chi square value $17.575,11.88,23.15,6.3,17.22$ and 4.56 respectively at $\mathrm{p} \leq 0.05 .^{13}$

The chi square association with selected demographic variables that is age, gender, BMI, regularity in taking medication for DM and physical activity are statistically significant having chi-square value $11.918,6.28,12.751,9.45$ and 5.22 with $(p \leq 0.05)$ and the mode of checking blood sugar is statistically not significant having chi-square value 4.24 with $(\mathrm{p} \leq 0.05)$.

The analysis shows by the chi-square test that there was significant association between fasting capillary, fasting venous and fasting plasma glucose value with selected demographic factors. ${ }^{14}$

\section{The relations of $\mathrm{HbA}_{\mathrm{ICv}}$ with demographic factors}

In analysis of ANOVA between age and $\mathrm{HbA}_{1 \mathrm{C}}$ value the calculated $F$ value (3.88) is lesser than tabulated $F$ value (5.91) at 0.05 level of significance. So it proves that there is an association between ages with $\mathrm{HbA}_{1 \mathrm{C}}$ value. In between Gender and $\mathrm{HbA}_{1 \mathrm{C}}$ value tabulated $\mathrm{F}$ value for the horizontal $(\mathrm{df}=2)$ and vertical $(\mathrm{df}=3)$ at 0.05 level of significance. The calculated $\mathrm{F}$ value (9.55) is lesser than tabulated $\mathrm{F}$ value (19.16) at 0.05 level of significance. So it proves that there is an association between genders with $\mathrm{HbA}_{1 \mathrm{C}}$ value. $\mathrm{BMI}$ and $\mathrm{HbA}_{1 \mathrm{C}}$ value that the tabulated $\mathrm{F}$ value for the horizontal $(\mathrm{df}=2)$ and vertical $(\mathrm{df}=12)$ at 0.05 level of significance. In between BMI with $\mathrm{HbA}_{1 \mathrm{C}}$ value the calculated $F$ value (3.88) is lesser than tabulated $F$ value (19.41) at 0.05 level of significance. ${ }^{15}$ So here it proves that there is an association between BMI with $\mathrm{HbA}_{1 \mathrm{C}}$ value. In between physical activity with $\mathrm{HbA}_{1 C}$ value the calculated $\mathrm{F}$ value (9.55) is lesser than tabulated $F$ value (19.16) at 0.05 level of significance. So it proves that there is an association between physical activities with $\mathrm{HbA}_{1 \mathrm{C}}$ value.

\section{Discussion}

The present study revealed that the mean score of capillary blood sugar was 145.4, mean score of venous blood sugar was 146, and mean score of Fasting blood sugar was 145 . So there were no so much difference between the venous, capillary and fasting plasma glucose both diabetic and non-diabetic patients. ${ }^{16}$ One can effectively manage the blood sugar by glucometer in self-monitoring. Also there was a correlation between venous blood, capillary blood, and fasting blood sugar. As Boyd conducted a study to determine the differences and of capillary and venous bedside glucose estimation in comparison with laboratory blood glucose analysis in Emergency Dept. patients $\mathrm{He}$ found Variation occurred between the glucometer and the laboratory blood glucose results. As Kumar G have shown the Correlation of capillary and venous blood glucometer with laboratory determination and noted an insignificant mean difference between the Capillary and Laboratory results. In this study it shows that there is an association between $\mathrm{HbA}$ c value and socio-demographic factors. As Gholamreza et al. ${ }^{17}$ have shown in a similar study on association between sociodemographic factors and diabetes mellitus. He showed a positive and significant correlation between fasting blood sugar and age, waist circumference, and BMI. 
In clinical practice, Clinicians need to recognize these factors and take steps to minimize their impact when assessing the accuracy of glucose meters used by their patients. Blood glucose meters must have sufficient accuracy to allow patients and clinicians to monitor glycemic control and then modify treatment accordingly.

\section{Conclusion}

Monitoring is an important component of routine diabetes care to maintain metabolic control and to aid in prevention of complications. There is a small but significant difference in the blood glucose results analyzed. So in clinical practice bedside blood glucose measurements through glucometer may be used by capillary derived specimens in the management of non-critically ill patients. However, a degree of caution should be exercised in the interpretation of bedside glucometer measurements as they may not be sufficiently accurate to replace laboratory blood glucose results.

There was significant association between $\mathrm{HbA}_{1 \mathrm{C}}$ value with age, BMI, physical activity and gender. So $\mathrm{HbA}_{1 \mathrm{C}}$ value is accurate measurement for determining the client with diabetic or not. But it cannot be tested in early diagnosed patients as it is the mean blood sugar value of the 2-3 month. The investigator noted that there was a need to have adequate technical and scientific knowledge among patients regarding the use of self-glucose monitoring device and there should be a standard guidelines regarding the use of it by which it will helpful for the self-management of blood sugar in their home.

\section{Acknowledgements}

None.

\section{Conflict of interest}

The author declares no conflict of interest.

\section{References}

1. American diabetes association. Tests of Glycemia in Diabetes Care. 2010;26(supply 1):106-108.

2. Tami Ross, Jackie Boucher, Belinda O Connell. American diabetes association consensus statement: self-monitoring of blood glucose. Diabetes Care. 1994;17:81-86.

3. Bode BW, Gross TM, Thornton KR, et al. Continuous glucose monitoring used to adjust diabetes therapy improves glycosylated hemoglobin: a pilot study. Diabetes Research and Clinical Practice. 1999;46(3):183190.
4. DCCT group. The effect of intensive treatment of diabetes on the development and progression of long-term complications in insulindependent diabetes mellitus. New England Journal of Medicine. 1993;329(140):977-986.

5. Shrestha L, Jha B, Yadav B, et al. Correlation between fasting blood glucose, postprandial blood glucose and glycated hemoglobin in noninsulin treated type 2 diabetic subjects. Sunsari Technical College Journal. 2012;1(1).

6. Boyd R, Leigh B, Stuart P. Capillary versus venous bedside blood glucose estimations. Emergency medicine journal. 2005;22(3):177-179.

7. Heisler Michele, Reynard RB, Rondey AH, et al. The Relative Importance of Physician Communication, Participatory Decision Making, and Patient Understanding in Diabetes Self-Management. Journal of General Internal Medicine. 2002;17(4):243-252.

8. International diabetes federation: Diabetes Atlas. International Diabetes Federation. Brussels: Springer; 2003.

9. The Diabetes prevention program research group. The diabetes prevention program: design and methods for a clinical trial in the prevention of type 2 diabetes. Diabetes Care. 1999;22(4):623-634.

10. Tonyushkina Ksenia, James H Nichols. Glucose meters: a review of technical challenges to obtaining accurate results. Journal of diabetes science and technology. 2009;3(4):971-980.

11. World health organization. Diabetes mellitus: Report of a WHO study group. Geneva: World health organization; 2014.

12. Bala Raghavendra GN, Bhat SG. Glucometer as a chairside device to assess blood glucose in periodontal patients. Journal of the International Clinical Dental Research Organization. 2010;2(3):126-130.

13. Kristensen GB, Monsen G, Skeie S, et al. Standardized evaluation of nine instruments for self-monitoring of blood glucose. Diabetes technology \& therapeutics. 2008;10(6):467-477.

14. St John A, Davis WA, Price CP, et al. The value of self-monitoring of blood glucose: a review of recent evidence. Journal of Diabetes and its Complications. 2010;24(2):129-141.

15. Oki Julie C, Douglas L Flora, William L Isley. Frequency and impact of SMBG on glycemic control in patients with NIDDM in an urban teaching hospital clinic. The Diabetes Educator. 1997;23(4):419-424.

16. Kotwal Narendra, Aditi Pandit. Variability of capillary blood glucose monitoring measured on home glucose monitoring devices. Indian journal of endocrinology and metabolism. 2012;16(2):248-251.

17. Gholamreza V, Mehdi Sedaghat, Hamidreza Joshaghani, et al. Association between socio-demographic factors and diabetes mellitus in the north of Iran: A population-based study. International Journal of Diabetes Mellitus. 2010;2(3):154-157. 